\title{
O MAPA DO TESOURO - "A GEOGRAFIA HUMANISTA: SUA TRAJETÓRIA 1950-1990"
}

El mapa del tesoro: “A Geografia Humanista: Sua Trajetória 1950-1990"

The treasure map: “A Geografia Humanista: Sua Trajetória 1950-1990"

\author{
Letícia Carolina Teixeira Pádua \\ Universidade Federal dos Vales do Jequitinhonha e Mucuri
}

A menina Geovana vivia com seu pai em uma casinha aconchegante que ficava no topo do morro mais alto da pequena cidade de Esmeraldina. Aprendeu desde tenra idade a tocar lindamente o piano herdado da vovó Ana e, ao mesmo tempo em que tocava, olhava pelas grandes janelas que emolduravam toda a cidade. Dona de uma grande sensibilidade, adorava reparar o vai e vem das pessoas lá em baixo, os ritmos dos carros e pedestres, as luzes do sol batendo no fim de tarde nas pedras da serra que se abria lá atrás, como que abraçando a cidade toda.

Cresceu em meio a muitos livros - seu pai era dono da única livraria de Esmeraldina. Todos os dias, depois da escola, Geovana ia para a livraria encontrar o pai, antes de irem juntos para casa. Nesta cidade a distância mais curta entre dois pontos não é uma linha reta, mas um zigue zague tortuoso, de modo que quem mora ali jamais repete os mesmos caminhos - não há rotinas repetitivas ali. Geovana, sempre curiosa, aproveitava os novos caminhos para observar e conhecer pessoas, pássaros, casas e prédios. Criar mapas ou decorar o caminho era inútil, já que amanhã, abriria-se outro. Só lhe restava, então, curtir cada um deles em cada momento que podia.

$\mathrm{Na}$ livraria ela também tinha muitos amigos que estavam sempre dispostos a levar Geo às mais variadas aventuras. É claro que ela tinha seus amigos preferidos: Marco Polo que a levara à China das maravilhas, Júlio Verne a quem ela seguiu para o centro da Terra, para dar uma volta no planeta em um balão e até à lua, Italo Calvino que tão bem descrevia as cidades que ninguém via (tendo fundado, inclusive, a sua!). Mas seu preferido entre todos era mesmo o Pequeno Príncipe, amigo do aviador Saint-Exupéry. Por anos, a passagem do geógrafo foi a sua preferida:

- Que livro é esse? Perguntou-lhe o principezinho. Que faz o senhor aqui?

- Sou geógrafo, respondeu o velho.

- Que é um geógrafo? Perguntou o principezinho.

Rev. Nufen: Phenom. Interd. | Belém, 9(2), 138-142, mai. - ago., 2017. 
- É um sábio que sabe onde se encontram os mares, os rios, as cidades, as montanhas, os desertos.

É bem interessante, disse o principezinho. Eis, afinal, uma verdadeira profissão! E lançou um olhar em torno de si, no planeta do geógrafo. Nunca havia visto planeta tão majestoso.

- O seu planeta é muito bonito. Haverá oceanos nele?

- Como hei de saber? Disse o geógrafo.

- Ah! (O principezinho estava decepcionado). E montanhas?

- Como hei de saber? Disse o geógrafo.

- E cidades, e rios, e desertos?

- Como hei de saber? Disse o geógrafo pela terceira vez.

- Mas o senhor é geógrafo!

- É claro, disse o geógrafo; mas não sou explorador. Há uma falta absoluta de exploradores. Não é o geógrafo que vai contar as cidades, os rios, as montanhas, os mares, os oceanos, os desertos. O geógrafo é muito importante para estar passeando. Não deixa um instante a escrivaninha. Mas recebe exploradores, interroga-os, anota as suas lembranças. E se as lembranças de alguns the parecem interessantes, o geógrafo estabelece um inquérito sobre a moralidade do explorador (SAINT-EXUPÉRY, 1988, p.54-56).

Ela logo decidiu que quando crescesse seria geógrafa - mas diferente deste! Ela não ia só anotar nos livros as coisas definitivas, como montanhas, desertos e rios. Ela faria uma geografia vibrante, que fala do efêmero, das pessoas, das sensações e do(s) mundo(s) que essas pessoas criavam, com o(s) qual(is) se relacionavam, os sentidos que as suas experiências tinham e até os valores e atitudes para com o ambiente.

No seu coração, Geovana tinha certeza de que não estava sozinha: que deviam existir muitos e muitos geógrafos que poderiam ajudá-la, pessoas atentas ao mundo sensível e que já deviam ter pensado muito sobre tudo isso. Assim, ela não teria que começar "do zero" e teria muitos companheiros na sua linda jornada.

Estava muito animada para fazer logo essa nova geografia, mas seu pai sempre dizia que tudo tem seu tempo: que ela devia aproveitar muito a infância que a vida adulta carrega responsabilidades e não tem lugar para devaneios.

Finalmente, Geo cresceu e entrou na Universidade. Claro que foi cursar Geografia!! Passaram-se alguns anos de curso e nada que aprendia parecia se aproximar muito do mundo sensível e vibrante que ela vivia. Na verdade, parecia que aquele geógrafo do Pequeno Príncipe tinha saído exatamente das mesmas carteiras onde hoje ela se

Rev. Nufen: Phenom. Interd. | Belém, 9(2), 138-142, mai. - ago., 2017. 
sentava. Um dia, então, em uma das aulas que ensinava a enumerar e classificar montanhas, rochas e minerais, Geovana explodiu em lágrimas:

- Professora, se eu não puder falar da beleza da montanha, se eu não puder subi-la como Petrarca, se as pedras não existirem e forem todas rochas, eu acho que estou mesmo no lugar errado - acho que Geografia não é um curso para mim. Nos meus devaneios, "O geógrafo que mede e calcula vem atrás: à sua frente, há um homem a quem se descobre a 'face da Terra'; há o pioneiro, o imigrante, ou simplesmente o homem tomado por um movimento insólito da Terra, tempestade, erupção, enchente. Há uma visão primitiva da Terra que o saber, em seguida, vem ajustar!!" (DARDEL, 2011, p.7).

- Geovana - respondeu a professora - acalme-se. Se servir de consolo, já ouvi dizer que lá pelas bandas do Rio de Janeiro fizeram um verdadeiro mapa do tesouro: uma dissertação, de mais de 500 páginas em que você encontrará os autores, as contribuições, as epistemologias e o percurso de muitos pensadores que se propuseram a fazer exatamente isso que você quer!

- Jura, Professora?!! Que felicidade!!! Eu sempre soube que não estava sozinha! Quero muito, então, encontrar este tesouro e, depois dele, percorrer os inúmeros caminhos que vão se abrir - um novo todos os dias, como na minha querida Esmeraldina. Diga-me, professora, como faço para ter acesso a esta dissertação?

- Infelizmente, eu não sei! Confesso que nunca tive um exemplar nas mãos e não conheço quem tenha.

- Vou procurar na internet, professora.

- Parece que a pesquisa foi defendida no início da década de 1990, portanto, é de um período em que a internet apenas engatinhava no Brasil. Pelo que soube, a dissertação foi datilografada a máquina de escrever que, portanto, só pode ser fotocopiado.

Geovana, então, começou a procurar: primeiro ela perguntou a todos os geógrafos e professores da Universidade que ela conhecia. Nada! Ela ligou para a biblioteca do Rio de Janeiro e eles informaram que não tinham trabalhos dessa época disponíveis atualmente. Já havia se passado mais de um ano na procura e Geo se formou. Desistiu então de encontrar o mapa do tesouro e começou até a duvidar de sua existência.

Alguns meses depois, ela foi a um congresso de geógrafos apresentar seu trabalho de conclusão de curso. O trabalho, na opinião dela, apenas cumpria os requisitos para a formatura, mas estava longe de refletir sua paixão, aquela geografia da experiência, do mundo ao seu redor. Lá, perguntando, ela finalmente encontrou um professor que tinha uma cópia e prometeu que enviaria pelos correios.

Geovana não se continha de alegria diante da possibilidade de, finalmente, ter o mapa do tesouro em suas mãos. Uma semana depois, Jaime o carteiro entregava um pesado e grosso envelope contendo uma cópia da pesquisa mais completa e incrível que

Rev. Nufen: Phenom. Interd. | Belém, 9(2), 138-142, mai. - ago., 2017. 
ela poderia imaginar!! Dali em diante, a geografia que Geovana sonhava ganhou contornos, história, autores, teorias, métodos e muitos caminhos...acima de tudo, agora, havia um nome: Geografia Humanista!

A fábula de Geovana sintetiza os percursos de muitos pesquisadores até chegar à Geografia Humanista e, sobretudo, a importância do livro "A Geografia Humanista: sua trajetória 1950-1990" lançado no último ano (2016), pela editora da Universidade Estadual de Londrina (Eduel).

Fruto da dissertação de Werther Holzer defendida no Programa de PósGraduação em Geografia da Universidade Federal do Rio de Janeiro em 1992, o lançamento em formato de livro preenche a enorme lacuna de circulação desta verdadeira obra-prima dos fundamentos da Geografia Humanista: sempre foram poucos os privilegiados que conseguiam ter uma cópia!

A Geografia Humanista passa por um momento riquíssimo no Brasil, de diversificação de suas bases teóricas e sua abrangência temática, no entanto os tradicionais manuais de história do pensamento geográfico ainda relegam a ela um papel secundário e descrevem um curto e empobrecido processo de amadurecimento. Quase sempre, estes manuais consideram a perspectiva humanista apenas como uma reação aos métodos quantitativos neopositivistas, com bases filosófico-epistemológicas difusas.

Este fato trouxe dois reflexos significativos nos trabalhos de quem pretendia se aproximar desta perspectiva: a primeira era a confusão ou mistura entre as bases teóricometodológicas do comportamentalismo (geografia da percepção) e a geografia humanista; o segundo é a aparente necessidade de sempre "começar" do mesmo ponto - voltando aos anos 1970 e ao contexto dos movimentos de contracultura estadunidenses que teriam dado origem a essa (contra)corrente.

O livro de Werther Holzer, de partida, resolve competente e definitivamente ambas as questões: primeiro demonstra a complexa a intricada rede de pensadores, matrizes e relações que levaram a uma geografia humanista fortemente embasada remetendo, inclusive, a antecedentes anteriores à década de 1950, de onde parte o título da obra e; ainda, é tão competente e detalhado na história de formação da geografia humanista, suas correntes, temas e seus antecedentes, que qualquer necessidade de recomeço se esvai diante da hercúlea tarefa já tão diligentemente destrinchada. Sem exageros, é possível dizer que a obra de Holzer liberta e incita os geógrafos humanistas (e aspirantes) para avançar temática, epistemológica e ontologicamente pelos caminhos, trilhas e matagais abertos ou a serem desvendados pelos nossos antecessores.

Tanto para iniciantes, quanto para "iniciados" ou profissionais de geografia humanista ela sempre será referência, inclusive, no pormenorizado relato sobre as relativamente diversas correntes, tendências e possibilidades já abertas, com particular 
atenção às contribuições fenomenológicas, hermenêuticas e existencialistas para a geografia, assim como as matrizes anglófonas e francófonas de pensamento que fundamentam a área.

Só nos resta, agora, aguardar o próximo cientista que terá coragem, fôlego e a competência de Holzer, para mapear as contribuições dos anos 1990 até os dias atuais.

\section{Referências}

Holzer, Werther. (2016). Geografia Humanista: sua trajetória 1950-1990. Londrina: Eduel.

Calvino, Ítalo. (1990). As cidades Invisíveis. Tradução Diogo Mainardi. São Paulo: Companhia das Letras, 1990.

. (2007). Por que ler os clássicos. Tradução Nilson Moulin. São Paulo: Companhia das Letras, 2007.

Dardel, Eric. (2011). O Homem e a Terra: natureza da realidade geográfica. Tradução Werther Holzer. São Paulo: Perspectiva.

Saint-Exupéry, Antoine. (1988). O Pequeno Príncipe. 32. ed. Tradução Dom Marcos Barbosa. Rio de Janeiro: Agir.

\section{Nota sobre a autora}

Letícia Carolina Teixeira Pádua. Doutora em Ciências Geografia pela Universidade de São Paulo (USP). Docente da Universidade Federal dos Vales do Jequitinhonha e Mucuri. E-mail: leticia.padua@ufvjm.edu.br. 